\title{
Genetic analysis of isoenzyme phenotypes using single tree progenies
}

\author{
Elizabeth Gillet and \\ Hans H. Hattemer
}

\author{
Abteilung für Forstgenetik und Forstpflanzenzüchtung, \\ Georg-August-Universität Göttingen, Büsgenweg 2, \\ 3400 Göttingen, Federal Republic of Germany
}

\begin{abstract}
A method of genetic analysis is proposed for determination of the mode of inheritance of environmentally and ontogenetically stable isoenzyme phenotypes as expressed in angiospermous forest trees. This method also applies to higher plant and animal species characterized by multiple matings of single female parents. The modes of inheritance considered are codominance in the absence and the presence of a (recessive) null allele. The analyzed material consists of zymograms of single maternal trees and their progenies (as seeds or seedlings) from open pollination. Such data is more easily obtained than controlled crosses and can represent the total variation in the population. The genetic analysis requires only the basic assumptions of classical Mendelian analysis, which make use only of the elementary mechanisms of meiosis and fertilization. Additional assumptions on the mating system, such as those required by the mixed mating model, are not needed. The results confirm the need for explicit genetic analysis of zymograms.
\end{abstract}

\section{THE NECESSITY OF GENETIC ANALYSIS OF ENZYME PHENOTYPES}

Complexities can arise in the interpretation of enzyme phenotypes, some of which are not at all visible in the zymograms alone. The following are of importance:

(a) Null alleles may exist which code for an enzyme of reduced or no activity in vivo, in vitro, or both. All types of null alleles are operationally recessive under routine procedures of laboratory analysis. Thus, if the modes of extraction and staining are not sensitive to the amount of active enzyme in the zymogram bands, an individual heterozygous for the null allele will appear to be homozygous for its active allele, and thus its null allele will not be detected. Furthermore, homozygosity for a null allele can be a lethal condition. Since only viable genotypes can be observed, analysis of the zymogram patterns alone can never reveal the existence of the null allele in such cases.

(b) Some alleles of gene loci controlling monomers code for double bands even in haploid tissue, as is known from both acid phosphatase and leucine aminopeptidase in conifer endosperm (Bergmann, 1973, 1974).
Therefore, it is not clear from the zymogram alone whether or not the presence of double bands can be interpreted as heterozygosity.

(c) The differences in electrophoretic mobility of the products of multiple gene loci controlling an enzyme system are not always greater than differences among allozymes (Stuber and Goodman, 1984, for 6-PGDH in maize). Thus the "zones" of a zymogram can overlap, causing problems in assigning the variation in one zone to the genetic variation at one gene locus. This is particularly true if the enzymes are monomers.

(d) Intergenic (or interlocus) heterodimers among multiple gene loci make it difficult to discriminate between zones of a given zymogram and thus between possible modes of transmission involving differing numbers of gene loci. $\mathrm{MDH}$ in pine seeds (O'Malley et al., 1979; ElKassaby, 1981; Müller-Starck, 1985a) and in spruce seeds (Cheliak et al., 1985; Pitel et al., 1987) may serve as an example. If intergenic heterodimers occur together with null alleles, as is the case with MDH in maize (Goodman et al., 1980) and Douglas-fir (El-Kassaby, 1981) as well as 6-PGDH in maize (Stuber and Goodman, 1984) and beech (Müller-Starck, personal communication), the zymograms may be uninterpretable. 
These complexities exist in only a few enzyme systems (cf. Shields et al., 1983). In most systems, information on the structure of the enzyme molecule helps to avoid ambiguities of genetic interpretation. For instance, appropriate biochemical methods consisting of inhibition of enzymes migrating into one of two different zones might be applied to prove that a certain enzyme system is controlled by two gene loci. Nevertheless, such complexities do arise, sometimes coinciding with post-translational modification of the isoenzyme phenotype. If they go unnoticed and thus are not incorporated into the postulated mode of inheritance, all further interpretations based on the erroneous mode of inheritance, such as characterization of the mating system, population differentiation, genetic distance between populations, or degree of heterozygosity, can be worthless. For this reason, genetic analysis of zymograms is essential.

\section{GENETIC ANALYSIS OF ENZYME PHENOTYPES IN TREE SPECIES}

In most tree species, classical Mendelian analysis, which requires offspring from controlled crosses as well as parental and offspring tissue of the same type and ontogenetic stage, is problematical. Controlled crosses in trees are often technically difficult to perform, and the numbers of offspring obtainable from controlled crosses are often too small for statistical testing. Yet even if controlled crosses succeed, the long generation intervals in trees imply that tissue of a particular type and ontogenetic stage can rarely be sampled from both parents and offspring. Nevertheless, since the expression of a number of enzymes has been found to be ontogenetically and environmentally stable, comparison of different ontogenetic stages in successive generations is often possible. Analysis of offspring at the earliest possible ontogenetic stage has the additional advantage of eliminating possible distortive effects of differential selection during later stages.

In coniferous tree species, segregation analysis of the haploid endosperm, which genetically represents the maternal gamete, allows observation of ordered genotypes in seed from open pollination of single trees (Bartels, 1971; Bergmann, 1973). This of course requires that the enzyme expression can be shown to be under complete genetic control, but controlled crossings are not necessary and ontogenetic stability of expression is not a prerequisite. Numerous investigations, too many to cite here (cf. Rudin, 1986), deal with the mode of inheritance of enzyme phenotypes in conifers.

In contrast, comparatively few studies have been published on the mode of inheritance of enzyme phenotypes in angiospermous tree species. For one, analysis of their tissue usually requires special extraction techniques (Torres, 1983; Arulsekar et al., 1983). Furthermore, analysis of the triploid endosperm depends upon the detectability of allele dosage differences (Schoen, 1979, 1980). Most existing studies have used progeny from controlled crossings. Among these are the investigations by Feret and Stairs (1971) and Feret (1972) on Ulmus species, Guzina (1978) and Rajora (1986) on Populus species, Kim (1979, 1980), Thiebaut et al. (1982), and Müller-Starck (1985b) on Fagus sylvatica, Wendel and Parks (1982) on Camellia japonica, Linares-Bensimón (1984) on Alnus glutinosa, and Arulsekar et al. (1985) on Juglans species. Genetic analysis of enzyme phenotypes in various fruit trees using controlled crossings was reviewed by Torres (1983). Several investigators utilized single tree offspring from open pollination but postulated the mode of inheritance on the basis of comparison with other species as well as comparison of total progeny and maternal gene frequencies (Brown et al. (1975) and Phillips and Brown (1980) on Eucalyptus species; reviewed in Moran and Bell (1983)) or comparison of the genotypic distributions within population samples with HardyWeinberg-proportions (Saidman and Naranjo (1982) in the leguminous tree Prosopis ruscifolia, O'Malley et al. (1988) in Bertholletis excelsa). Brotschol (1983) also used the former method in her investigation of Liriodendron tulipifera, additionally testing hypotheses against a $1: 1$ segregation ratio of the maternal alleles in offspring possessing an allele not found in the maternal tree, wherever possible. Finkeldey (1988) investigated single-tree offspring from open pollination of Quercus petraea, basing choice of mode of inheritance in cases of doubt on the results of a paternity analysis.

New methods of genetic analysis are needed that comply with the reproductive biology of angiospermous tree species in that they allow the inference of genotypes without requiring sexually differentiated tissue and consider the necessity for comparison of different ontogenetic stages in successive generations. Such methods must use unordered genotypes and be based on a combination of genealogical and population data as compensation for the generally limited opportunities for performing controlled crosses. Such a method, 
utilizing zymograms of maternal trees and their seed offspring from open pollination, will be presented below.

In this connection, the paper of Brown et al. (1975) on the estimation of the mating system in a Eucalyptus species using single tree progenies must be mentioned. These authors are sometimes cited as having presented a method of genetic analysis. Instead, based on the mixed mating model, they infer the unknown maternal genotype using the "known" genotypes of a progeny sample. The progeny genotypes had been previously inferred from the zymograms, apparently without consideration of the proportions of different phenotypes within each progeny set. Due to the incorporation of numerous prior estimates stemming from the mixed mating model, it is questionable whether an incorrect hypothesis on the mode of inheritance would be revealed in the course of analysis.

\section{A METHOD OF GENETIC ANALYSIS USING SINGLE TREE PROGENIES}

\section{Basic requirements}

Assume that the enzyme system under study is under complete genetic control and that the expression is ontogenetically stable (e.g. observable in both leaf and seed tissue). In cases where the genetic control has not yet been established, it will often become apparent or be disproven in the course of the investigation. Furthermore, suppose that an hypothesis on the mode of inheritance of enzyme phenotypes involving a single gene locus has been inferred from zymograms.

A regularly segregating gene locis is assumed to fulfill the following three requirements, subsequently referred to as "requirements $\triangleright$ ", which also underlie classical Mendelian analysis:

(i) regular meiotic segregation during egg production;

(ii) random fertilization of the eggs by each pollen (haplo) type;

(iii) absence of differential viability selection in the offspring prior to the investigation.

Denoting

$$
\begin{aligned}
P\left(A_{l}^{q}\right):= & \text { probability that an egg cell has } \\
& \text { the allele } A_{l},
\end{aligned}
$$

(i) implies $P\left(A_{i}^{q}\right)=P\left(A_{j}^{q}\right)=\frac{1}{2}$ for maternal genotype $A_{i} A_{j}(i \neq j)$. In terms of the conditional probabilities

$$
\begin{aligned}
P\left(A_{l}^{\curvearrowright} A_{m}^{\delta} \mid A_{m}^{\delta}\right)= & \text { (conditional) probability that } \\
& \text { a zygote having paternal allelic }
\end{aligned}
$$

contribution $A_{m}$ will also have maternal allelic contribution $A_{l}$, $=P\left(A_{l}^{\delta} A_{m}^{\delta}\right) / P\left(A_{m}^{\delta}\right)$, where $P\left(A_{m}^{\delta}\right)=$ probability that an egg cell will be fertilized by a pollen grain having the allele $A_{m}$ to form a zygote, and

$P\left(A_{l}^{\circ} A_{m}^{\delta}\right)=$ probability that a zygote have ordered genotype $A_{l}^{\delta} A_{m}^{\delta}$, i.e. maternal allelic contribution $A$ and paternal allelic contribu. tion $A_{m}$,

(ii) implies $\left.P\left(A_{l}^{\circ} A_{k}^{\delta}\right) \mid A_{k}^{\delta}\right)=P\left(A_{i}^{\circ}\right)$ for all alleles $A_{i}$ and $A_{k}$. The most important consequence of (i) and (ii) on which all further considerations will be based is that, for maternal genotype $A_{i} A_{j}$,

$$
\begin{aligned}
& P\left(A_{i}^{q} A_{k}^{\delta}\right)=P\left(A_{i}^{\S} A_{k}^{\delta} \mid A_{k}^{\delta}\right) \cdot P\left(A_{k}^{\delta}\right) \\
& =P\left(A_{i}^{\circ}\right) \cdot P\left(A_{k}^{\circ}\right) \\
& =P\left(A_{j}^{\circ}\right) \cdot P\left(A_{k}^{\delta}\right) \\
& =P\left(A_{j}^{\rho} A_{k}^{\delta} \mid A_{k}^{\delta}\right) \cdot P\left(A_{k}^{\delta}\right) \\
& =P\left(A_{j}^{\circ} A_{k}^{\delta}\right) \text {. }
\end{aligned}
$$

In words, this means that any allele $A_{k}$ contained in the local pollen pool will have equal chances of fertilizing egg cells with either of the two maternal alleles.

\section{Material}

Leaf or bud tissue and seed samples from single trees, ideally belonging to a single population, are collected and the zymograms obtained by electrophoresis. Previously obtained zymograms of prospective maternal trees can give an indication of the variability present in the population and thus aid in selection of those trees which can be expected to yield the most information.

\section{Method}

The method consists in the formulation of necessary conditions which must be fulfilled in each progeny set under

-a given hypothesis as to the mode of inheritance of an isoenzyme phenotype,

- the postulated maternal genotype, and

- the fulfilment of the requirements $\square$.

Due to the differing genotype-to-phenotype relationships implied by different modes of gene action, the conditions will depend upon the postulated dominance relationships between alleles. 
Here the two variants most commonly encountered in the single-locus inheritance of enzyme phenotypes will be considered, namely

codominance between all alleles; and

the presence of a recessive null allele and

codominance between active alleles.

Following the patterns laid out below, analogous conditions for more complex modes of gene action, such as mixtures of dominance and codominance in an allelic series, should not be difficult to derive.

\section{Single-locus codominant mode of inheritance}

The necessary conditions are as follows, where

$P\left(A_{l} A_{m}\right)$ - probability that a zygote have unordered genotype $A_{l} A_{m}$ $=\left[P\left(A_{l}^{Q} A_{m}^{\delta}\right)+P\left(A_{m}^{q} A_{l}^{\delta}\right)\right] \cdot \frac{1}{2}\left(2-\delta_{l m}\right)$,

where $\delta_{l m}-1$ if $l=m$ and $\delta_{l m}=0$ otherwise (Kronecker delta), and

$$
\begin{aligned}
N_{l m}= & \text { observed number of offspring with } \\
& \text { phenotype } A_{l} A_{m} \text { : }
\end{aligned}
$$

If a maternal tree is

(C1) homozygous $A_{i} A_{i}$, then each offspring must have the allele $A_{i}$

(C2) heterozygous $A_{i} A_{j}(i \neq j)$, then each offspring must have the allele $\boldsymbol{A}_{i}$ or $\boldsymbol{A}_{j}$, and it holds that

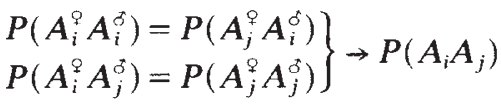

$$
\begin{aligned}
& -P\left(A_{i} A_{i}\right)+P\left(A_{j} A_{j}\right)
\end{aligned}
$$

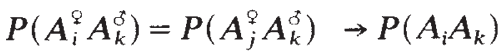

$$
\begin{aligned}
& =P\left(A_{j} A_{k}\right) \quad(k \neq i, j) .
\end{aligned}
$$

This formal approach was suggested by H.-R. Gregorius. Obviously, a seed must contain one of the maternal alleles. However, since only unordered genotypes can be inferred, the above probabilities for ordered genotypes among the offspring of a heterozygous maternal tree must be combined, as indicated by the brackets. These probabilities can then be used to test the observed numbers of offspring possessing each of the unordered genotypes with the expectation, as is summarized in table 1.

\section{Single-locus with recessive null allele and codominance between active alleles}

Rejection of an hypothesis of codominance by the above method could be caused by an undetected
Table 1 Genetic analysis using single tree progenies. Singlelocus codominant mode of inheritance

\begin{tabular}{lll}
\hline $\begin{array}{l}\text { Proposed } \\
\text { maternal } \\
\text { genotype }\end{array}$ & $\begin{array}{l}\text { Possible } \\
\text { genotypes } \\
\text { of offspring }\end{array}$ & $\begin{array}{l}\text { Expected relationship } \\
\text { between observed numbers } \\
\text { of offspring phenotypes }\end{array}$ \\
\hline$A_{i} A_{i}$ & $\begin{array}{l}A_{i} A_{i} \\
A_{i} A_{k}(k \neq i)\end{array}$ \\
$A_{i} A_{j}$ & $A_{i} A_{i}$ & \\
$(i \neq j)$ & $A_{j} A_{j}$ & $N_{i j}=N_{i i}+N_{j j}$ \\
& $A_{i} A_{j}$ & $N_{i k}=N_{j k}(k \neq i, j)$ \\
& $A_{i} A_{k}$ & \\
\hline
\end{tabular}

null allele, which is present only in a heterozygous state in the population. If a phenotypically "homozygous" maternal tree were actually heterozygous for a null allele, then offspring could be found which seem to be homozygous for a non-maternal allele. On the other hand, a null allele among the paternal trees would cause an excess of offspring phenotypically "homozygous" for a maternal allele.

The inclusion of a recessive null allele in the hypothesis on the mode of inheritance therefore requires a more involved method of analysis. Nevertheless, the above-mentioned consequence of the requirements for a regularly segregating gene locus, namely that for heterozygous maternal genotype $A_{i} A_{j}$ any allele $A_{k}$ contained in the local pollen pool will have equal chances of fertilizing egg cells with either of the two maternal alleles, is still valid in the presence of a null allele. The necessary conditions are as follows, where

$$
\begin{aligned}
P\left(A_{l}-\right)= & \text { probability that a zygote have phenotype } \\
& A_{l}-\text {, i.e. genotype } A_{l} A_{l} \text { or } A_{l} A_{0} \\
N_{l}-= & \text { observed number of offspring with } \\
& \text { phenotype } A_{l}-\text {, respectively: }
\end{aligned}
$$

If a maternal tree is

$\left(\mathrm{C}^{\circ}\right)$ homozygous $A_{0} A_{0}$ for a null allele $A_{0}$, then each offspring must have the allele $A_{0}$;

$\left(\mathrm{C} 2^{\circ}\right)$ homozygous $A_{i} A_{i}$ for an active allele $A_{i}$ $(i \neq 0)$, then each offspring must have the allele $A_{i}$;

$\left(\mathrm{C}^{\circ}\right)$ heterozygous $A_{i} A_{0}$ for a null allele $A_{0}$ and an active allele $A_{i}(i \neq 0)$, then each offspring must have the allele $A_{0}$ or $A_{i}$, and it holds that

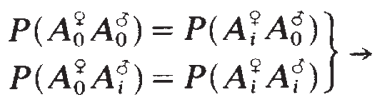

$$
\begin{aligned}
& P\left(A_{0} A_{0}\right) \leqq P\left(A_{i}-\right) \\
& P\left(A_{0}^{\uparrow} A_{k}^{\dagger}\right)=P\left(A_{i}^{९} A_{k}^{\delta}\right) \rightarrow \\
& P\left(A_{k}-\right)=P\left(A_{i} A_{k}\right) \quad(k \neq 0, i) ;
\end{aligned}
$$


$\left(\mathrm{C}^{\circ}\right)$ heterozygous $A_{i} A_{j}$ for two active alleles $A_{i}$ and $A_{j} \quad(0 \neq i \neq j \neq 0)$, then (a) each offspring must have the allele $A_{i}$ or $A_{j}$, and it holds that

$$
\begin{aligned}
& P\left(A_{i}^{q} A_{0}^{\sigma}\right)=P\left(A_{j}^{q} A_{0}^{\delta}\right) \\
& \left.P\left(A_{i}^{q} A_{i}^{\delta}\right)=P\left(A_{j}^{q} A_{i}^{\delta}\right)\right\} \\
& \left.P\left(A_{i}^{q} A_{j}^{\delta}\right)=P\left(A_{j}^{q} A_{j}^{\delta}\right)\right\} \rightarrow \\
& P\left(A_{i} A_{i}\right) \leqq P\left(A_{i}-\right)+P\left(A_{j}-\right) \\
& P\left(A_{i}^{q} A_{k}^{\delta}\right)=P\left(A_{j}^{q} A_{k}^{\delta}\right) \rightarrow \\
& P\left(A_{i} A_{k}\right)=P\left(A_{j} A_{k}\right) \quad(k \neq 0, i, j) .
\end{aligned}
$$

A maternal allele must, of course, be present. However, if the maternal tree contains a null allele, then all "homozygous" phenotypes can appear within the progeny. The probabilities for ordered genotypes must now be combined not only according to the proposed unordered genotypes but also to the phenotypes. The observed numbers of offspring with each of the phenotypes can be tested for conformity to these probabilities, as is summarized in table 2 .

Table 2 Genetic analysis using single tree progenies. Singlelocus mode of inheritance with a recessive null allele and codominance between active alleles

\begin{tabular}{lll}
\hline $\begin{array}{ll}\text { Proposed } \\
\text { maternal } \\
\text { genotype }\end{array}$ & $\begin{array}{l}\text { Possible } \\
\text { phenotypes } \\
\text { of offspring }\end{array}$ & $\begin{array}{l}\text { Expected relationship } \\
\text { between observed numbers } \\
\text { of offspring phenotypes }\end{array}$ \\
\hline$A_{0} A_{0}$ & $A_{0} A_{0}$ & \\
& $A_{k}-(k \neq 0)$ & \\
$A_{i} A_{i}$ & $A_{i}-$ & \\
$(i \neq 0)$ & $A_{i} A_{k}(k \neq 0, i)$ & \\
$A_{i} A_{0}$ & $A_{0} A_{0}$ & $N_{00} \leqq N_{i-}$ \\
$(i \neq 0)$ & $A_{i-}$ & $N_{k-}=N_{i k}(k \neq 0, i)$ \\
& $A_{k-}$ & \\
$A_{i} A_{j}$ & $A_{i} A_{k}(k \neq 0, i)$ & \\
$(0 \neq i \neq j \neq 0)$ & $A_{i-}$ & $A_{j-}$ \\
& $A_{i} A_{j}$ & $N_{i j} \leqq N_{i-}+N_{j-}$ \\
& $A_{i} A_{k}$ & $N_{i k}=N_{j k}(k \neq 0, i, j)$ \\
& $A_{j} A_{k}(k \neq 0, i, j)$ & \\
\hline
\end{tabular}

Null alleles have in some cases been shown to be sublethal or even lethal in a homozygous state. For example, for mitochondrial $\mathrm{MDH}$ in maize, homozygosity for a null allele at all of the three controlling loci is lethal, while a single active allele at any one of the loci suffices for viability (Goodman et al., 1981). Thus at any one of the three loci the number of offspring homozygous for the respective null allele will be reduced by the number of non-viable offspring homozygous for the null allele at all three loci. It is interesting to note that reduced viability of carriers of null alleles will not lead to rejection of the null allele hypothesis by the above method, as long as the viability of the null allele homozygote does not exceed the viability of any of the null allele heterozygotes.

\section{GENERAL PROCEDURE OF GENETIC ANALYSIS}

The results of the previous section suggest the following procedure for the genetic analysis of zymograms in populations of angiospermous trees:

(i) Trees in the population are chosen by some plan (not necessarily randomly) in the hopes that they will represent as much genetic variability as possible (for example, if neighboring trees are expected to be closely related, then the chosen trees should be widely scattered throughout the population);

(ii) tissue (e.g. buds or leaves) of each of the chosen trees is analyzed electrophoretically for the enzyme system under study;

(iii) hypotheses as to the mode of inheritance of the observed phenotypes are constructed on the basis of these zymograms;

(iv) representatives of each of the proposed genotypes are selected, and their respective seed progenies from open pollination are collected;

(v) genetic analysis of the individual progeny sets is performed according to the method in the previous section.

This procedure has been applied to Castanea sativa (Fineschi et al., submitted).

\section{EXAMPLES}

Single-tree harvesting of offspring from open pollination or, in other species, analogous collection of a single maternal individual's offspring cohort with father(s) of unknown phenotype presents few technical problems as compared to the performance of controlled crosses. It therefore seems surprising that the phenotypic distributions within such offspring sets have, judging from the difficulty in finding published data, rarely been used in genetic analysis. (An exception is found in species possessing haploid tissue at some ontogenetic stage, e.g., the maternally-inherited haploid endosperm in conifer seeds, as discussed above.

\section{Example 1}

One exception is a study by Thiebaut et al. (1982) on beech. They support their hypothesis on the 
existence of a null allele at a peroxidase locus by examination of offspring from open pollination of a single tree. Renaming alleles, the postulated maternal genotype is $A_{2} A_{0}$ (case $\left(\mathrm{C}^{\circ}\right)$ in previous section), and the numbers of the offspring phenotypes are: $N_{00}=0, N_{2-}=2, N_{1-}=12$, and $N_{12}=11$ (their table 5). $\left(\mathrm{C}^{0}\right)$ holds, since $N_{00}<$ $N_{2-}$ and the ratio $N_{1-}: N_{12}$ of $12: 11$ is as close as possible to $1: 1$. These results give no reason to reject the hypothesized mode of inheritance nor to doubt the fulfilment of requirements $\triangleright$.

\section{Example 2}

Christiansen et al. (1977) conducted population genetic studies on the eelpout Zoarces viviparus L. Maternal fish were grouped by age and genotype at a single gene locus with two codominant alleles (EstIII). For each such group, the offspring of a single year were pooled and the genotypic structure given. Arbitrarily choosing the first of their numerous observations (their table 1, Age 2 mothers in 1971), it is seen that this situation is an example of (C1) and (C2):

\begin{tabular}{cccrc}
$\begin{array}{c}\text { Maternal } \\
\text { genotype }\end{array}$ & \multicolumn{4}{c}{ Offspring of type } \\
11 & 12 & 22 & $\begin{array}{c}\text { Pearson } \chi^{2} \text {-test } \\
\text { of }(\mathrm{C} 2 \mathrm{~b})\end{array}$ \\
\hline 11 & 64 & 114 & & \\
12 & 94 & 281 & 185 & $\chi^{2}=0.01 \mathrm{~ns}$ \\
22 & & 190 & 307 &
\end{tabular}

Spot-checking of their other observations for groups of heterozygous maternal animals showed conformity with the expectation of $N_{12}=N_{11}+N_{22}$ in all cases. Thus there is no reason to question the correctness of the postulated mode of inheritance nor the fulfilment of requirements $\triangle$ above.

\section{Example 3}

Fineschi et al. (submitted) studied single tree offspring from open pollination in a Castanea sativa Mill. population. Analysis of the offspring phenotypes following the above method suggested the presence of a null allele in the population at one gene locus. As an example of $\left(\mathrm{C}^{\circ}\right)$, a maternal tree of proposed genotype $A_{1} A_{3}$ had offspring phenotypes $N_{1-}=7, N_{3-}=14, N_{13}=6, N_{12}=13$, and $N_{23}=12 .\left(\mathrm{C}^{0}\right)$ is fulfilled, since $N_{13}<$ $N_{1-}+N_{3-}$ and $N_{12}: N_{23}=13: 12$. (If the null allele in the population had not been noticed and (C2) tested instead, the ratio $N_{13}:\left(N_{1-}+N_{3-}\right)$ of $6: 21$ would have correctly led to rejection of that mode of inheritance.)
Acknowledgement The authors are indebted to S. Fineschi and M. E. Malvolti, whose enzyme investigation of bud tissue of single chestnut trees (of the angiospermous species Castanea sativa Mill.) and their seed from open pollination motivated these considerations and to H.-R. Gregorius for suggesting the formal approach to the genetic analysis.

\section{REFERENCES}

ARULSEKAR, S., PARFITT, D. E. AND MCGRANAHAN, G H. 1985. Isozyme gene markers in Juglans species. J. Hered., $76,103-106$.

BARTELS, H. 1971. Genetic control of multiple esterases from needles and macrogametophytes of Picea abies. Planta, 99 , 283-289.

BERGMANN, F. 1973. Genetische Untersuchungen bei Picea abies mit Hilfe der Isoenzym-Identifizierung. II. Genetische Kontrolle von Esterase- and Leucin-aminopeptidase-Enzymen im haploiden Endosperm ruhender Samen. Theor. Appl. Genet, 43, 222-225.

BERGMANN, F. 1974. The genetics of some isoenzyme systems in spruce endosperm (Picea abies). Genetika, 6, 353-360.

BROTSCHOL, J. V. 1983. Allozyme variation in natural populations of Liriodendron tulipifera L. Doctoral dissertation, Dept. of Genetics and Forestry, North Carolina State Univ.

BROWN, A. H. D, MATHESON, A. C. AND ELDRIDGE, K. G. 1975. Estimation of the mating system of Eucalyptus obliqua L'Herit. by using allozyme polymorphisms. Aust. J. Bot., 23, $931-949$.

CHELIAK, W. M., PITEL, J. A. AND MURRAY, G. 1985. Population structure and the mating system of white spruce. Can. J. For. Res., 15, 301-308.

CHRISTIANSEN, F. B., FRYDENBERG, O. AND SIMONSEN, V. 1977. Genetics of Zoarces populations. X. Selection component analysis of the EstIII polymorphism using samples of successive cohorts. Hereditas, 87, 129-150.

EL-KASSABY, Y. A. 1981. Genetic interpretation of malate dehydrogenase in some conifer species. $J$. Hered. 72, 451-452.

FERET, P. P. 1972. Peroxidase isoenzyme variation in interspecific elm hybrids. Can. J. For. Res., 2, 264-270.

FERET P. P. AND STAIRS, G. R. 1971. Peroxidase inheritance in Siberian elm. Forest Sci., 17, 472-475.

FINKELDEY, R. 1988. Simultane Vaterschaftsanalyse und Genidentifikation bei Waldbäumen. Theorie und experimentelle Überprüfung am Beispiel der Traubeneiche (Quercus petraea Lieblein). Diplom thesis, Universität Götingen.

GOODMAN, M. M., NEWTON, K. J. AND STUBER, C. W. 1981. Malate dehydrogenase: Viability of cytosolic nulls and lethality of mitochondrial nulls in maize. Proc. Natl. Acad. Sci. USA, 78, 1783-1785.

GOOIMAN. M. M., NEWTON, K. J. AND STUBER, C. W. 1981. F. M. 1980. Genetic control of malate dehydrogenase isozymes in maize. Genetics, 94, 153-168.

GUZINA, V. 1978. Genetic control of isoperoxydases Px- $\mathbf{A}_{1}$, $\mathrm{Px}-\mathrm{A}_{2}, \mathrm{Px}-\mathrm{B}_{1}$ and $\mathrm{Px}-\mathrm{B}_{2}$ in aspen (Populus tremulus L.). Annales Forestales, 8, 51-90.

KIM, Z.-S. 1979. Inheritance of leucine aminopeptidase and acid phosphatase isozymes in beech (Fagus sylvatica L.). Silvae Genetica, 28, 68-71.

K1M, Z.-S. 1980. Veränderung der genetischen Struktur von Buchenpopulationen durch Viabilitätsselektion im Keimlingsstadium. Göttingen Research Notes in Forest Genetics, No. 3. 
LINARES-BENSIMÓN, C. 1984. Versuche zur Viabilitätsselektion an Enzymgenloci bei Alnus glutinosa (L.) Gaertn. Gottingen Research Notes in Forest Genetics, No. 7.

MORAN, G. F. AND BELL, J. C. 1983. Eucalyptus. In: Tanksley, S. D. and Orton, T. J. (eds) Isozymes in Plant Genetics and Breeding, Part B. Elsevier, Amsterdam, Oxford, New York, pp. 423-441.

MÜLLER-STARCK, G. $1985 a$. Reproductive success of genotypes of Pinus sylvestris L. in different environments. In Gregorius, H.-R. (ed.) Population Genetics in Forestry. Lecture Notes in Biomathematics, 60, Springer-Verlag, Berlin, Heidelberg, New York, Tokyo, pp. 118-133.

MÜLLER-STARCK, G. 1985 $b$. Genetic differences between "tolerant" and "sensitive" beeches (Fagus sylvatica L.) in an environmentally stressed adult forest stand. Silvae Genetica, 34, 241-247.

MALLEY, D. M., ALLENDORF, F. W. AND BLAKE, G. M. 1979. Inheritance of isozyme variation and heterozygosity in Pinus ponderosa. Biochem. Genet. 17, 233-250.

MALLEY, D. M., BUCKLEY, D. P., PRANCE, G. T. AND BAWA, K. S. 1988. Genetics of Brazil nut (Bertholletia excelsa Humb. \& Bonpl.: Lecythidaceae) 2. Mating system. Theor. Appl. Genet., 76, 929-932.

IILliPS, M. A., AND BROWN, A. H. D., 1980. Mating system and hybridity in Eucalyptus pauciflora. Aust. J. Biol. Sci., 30, 337-344.

PITEL, J. A., CHELIAK, W. M. AND BARRETT, J. 1987. Inheritance of allozymes in a black spruce diallel cross. Silvae Genetica, $36,149-153$.

RAJORA, O. P. 1986. Studies on genetics and relationships of Populus deltoides Marsh., P. nigra L. and P. maximowiczii Henry using isozymes, pollen competition and leaf morphology. Doctoral dissertation, University of Toronto.
RUDIN, D. 1986. Developmental trends in the field of biochemical genetics of forest trees. In Proc. 18th IUFRO World Congress, Ljubljana, 1986, Vol. 2, pp. 577-588.

SAIDMAN, B. O. AND NARANJO, C. A. 1982. Variaciones de esterasas en poblaciones de Prosopis ruscifolia (Leguminosae). Mendeliana, 5, 61-70.

SCHOEN, D. J. 1979. An angiosperm analogue to megagametophyte analysis. J. theor. Biol., 79, 543-546.

SCHOEN, D. J. 1980. Half tetrad analysis in angiospermis. $J$. theor. Biol., 86, 315-322.

SHIELDS, D. R., ORTON, T. J. AND STUBER, C. W. 1983. An outline of general resource needs and procedures for the electrophoretic separation of active enzymes from plant tissues. In Tanksley, S. D. and Orton, T. J. (eds) Isozymes in Plant Genetics and Breeding, Part A. Elsevier, Amsterdam, Oxford, New York, pp. 443-463.

STUBER, C. W. AND GOODMAN, M. M. 1984. Inheritance, intracellular localization, and genetic variation of 6-phosphogluconate dehydrogenase in maize. Maydica, 29, 453 471.

THIEBAUT, B., LUMARET, R. AND VERNET, P. 1982. The bud enzymes of beech (Fagus sylvatica L). Genetic distinction and analysis of polymorphisms in several French populations. Silvae Genetica, 31, 51-60.

TORRES, A. M. 1983. Fruit trees. In Tanksley, S. D. and Orton T. J. (eds) Isozymes in Plant Genetics and Breeding, Part B. Elsevier, Amsterdam, Oxford, New York, pp. 401-421.

WENDEL, J. F. AND PARKS, C. R. 1982. Genetic control of isozyme variation in Camellia japonica L. (Theaceae). J. Hered., 73, 197-204. 